\title{
Desenvolvimento inicial de mudas de Butia odorata (Barb. Rodr.) Noblick cultivadas em recipientes ${ }^{1}$
}

\author{
Claudimar Sidnei Fior ${ }^{2}$, Amanda Pezzi ${ }^{3}$, Sergio Francisco Schwarz ${ }^{4}$ \\ http://dx.doi.org/10.1590/0034-737X201461050014
}

\begin{abstract}
RESUMO
Butia odorata (Barb.Rodr.) Noblick (butiazeiro) é uma palmeira nativa do sul do Brasil, com grande demanda para usos ornamental e agroindustrial. O objetivo deste estudo foi avaliar o desenvolvimento inicial de mudas de butiazeiro, em recipientes com diferentes composições de substratos. O experimento foi desenvolvido em casa de vegetação sem controle de temperatura e umidade. Foram utilizadas mudas com 60 dias após a germinação, e avaliados os substratos, em cinco proporções, dos componentes casca de arroz carbonizada e casca de pinus. Em etapa posterior, monitorou-se o efeito do $\mathrm{pH}$ do substrato no desenvolvimento das mudas mantidas nos mesmos recipientes e tratamentos. Para tanto, as plantas foram distribuídas em igual número e representação dos tratamentos, em quatro grupos, com quatro níveis de $\mathrm{pH}$ do substrato $(4,0 ; 4,9 ; 5,8$ e 6,7). Noventa dias após o início da primeira etapa, e 161 dias após o início da segunda, foram avaliados o desenvolvimento das plantas, a condutividade elétrica e o pH dos substratos. Na primeira etapa, constatou-se diferença entre os tratamentos somente para altura das plantas e pH do substrato, ambas relacionadas diretamente com a proporção de casca de pinus na formulação. Na segunda etapa, a composição do substrato foi determinante para o maior desenvolvimento das mudas. Somente o número de folhas não apresentou diferença significativa entre os tratamentos. Contudo, para todas as variáveis, a presença de casca de pinus, mesmo em baixa proporção, foi suficiente para favorecer o desenvolvimento vegetativo.
\end{abstract}

Palavras-chave: butiazeiro, adubação, substrato, palmeira nativa, Arecaceae.

\section{ABSTRACT}

\section{Initial development of Butia odorata (Barb. Rodr.) Noblick seedlings grown in containers}

Butia odorata(Barb.Rodr.) Noblick(pindo palm) is a palm tree native from southern Brazil, with a great demand for ornamental and agroindustry use. The objective of this study was to test the initial development of pindo palm seedlings in different substrate compositions inside containers. The experiment was conducted in a greenhouse without temperature or humidity control. It was used seedlings at $60^{\text {th }}$ day after germination, and substrates were tested in five proportions of carbonized rice husks and pine bark. After that, the effect of $\mathrm{pH}$ of the substrates was monitored on the growth of plants maintained in the same containers and treatments. Plants were distributed in equal number and representation of treatments in four groups with four levels of $\mathrm{pH}$ in the substrate $(4.0 ; 4.9 ; 5.8$ and 6.7). Ninety days after the beginning of the first stage and 161 days after the beginning of the second, the plants growth and the electrical conductivity and $\mathrm{pH}$ of the substrates were measured. Diference among treatments was found in the first state only for plant height and $\mathrm{pH}$ of the substrate, both directly related to the proportion of pine

\footnotetext{
Recebido para publicação em 21/01/2013 e aprovado em 25/02/2014.

${ }^{1}$ Este trabalho é parte da tese de doutorado do primeiro autor, realizada com apoio financeiro da FAPERGS e do CNPq.

Engenheiro-Agrônomo, Doutor. Departamento de Horticultura e Silvicultura, Universidade Federal do Rio Grande do Sul, Avenida Bento Gonçalves, 7712, Caixa Postal 15100, 91501-970, Porto Alegre, Rio Grande do Sul, Brasil. csfior@ufrgs.br (autor para correspondência).

${ }^{3}$ Bióloga. Mestranda do Programa de Pós-graduação em Fitotecnia da Universidade Federal do Rio Grande do Sul, Avenida Bento Gonçalves, 7712, Caixa Postal 15100, $91501-970$, Porto Alegre, Rio Grande Do Sul, Brasil. amandapezzi68@gmail.com

${ }^{4}$ Engenheiro-Agrônomo, Doutor. Departamento de Horticultura e Silvicultura, Universidade Federal do Rio Grande do Sul, Avenida Bento Gonçalves, 7712, Caixa Postal 15100, 91501-970, Porto Alegre, Rio Grande do Sul, Brasil. schwarz@ufrgs.br
} 
bark. On the second stage, substrate composition was decisive for the larger development of the seedlings. Only the number of leaves was not significantly different among treatments. However, for all variables, the presence of pine bark, even at low proportion was sufficient to promote vegetative growth.

Key words:Arecaceae, fertilization, native pal, Pindo palm, substrate.

\section{INTRODUÇÃO}

O butiazeiro [Butia odorata (Barb. Rodr.) Noblick] é uma palmeira de porte arbóreo, característica do Uruguai e do extremo sul do Brasil. Tem grande demanda para usos ornamental e agroindustrial. Os frutos podem ser processados (Tonietto et al., 2009) e as fibras têm emprego artesanal e industrial (Geymonat \& Rocha, 2009).

No Rio Grande do Sul, ocorrem oito espécies do gênero: B. odorata (Barb. Rodr.) Noblick, $B$. eriospatha (Mart. Ex Drube) Becc., B. paraguayensis (Barb. Rodr.) L. H. Bailey, B. yatay (Mart.) Becc., B. lallemantii Deble \& Marchiori, B. microspadix Burret, B. catarinensis Noblick \& Lorenzi (Lorenzi et al., 2010) e Butia witeckii K. Soares \& S. Longhi (Soares \& Longhi, 2011).

Trabalhos recentes têm demonstrado o grande potencial dos frutos de Butia spp para fabricação de inúmeros produtos, pela agroindústria. No entanto, avanços neste sentido são limitados pela falta de conhecimento sobre a produção em escala e manejo de mudas. Além disso, são inúmeros os casos de flagrantes de extração ilegal de exemplares adultos de butiazeiros, para uso em paisagismo. Estima-se que alguns desses espécimes apresentem idade superior a cem anos, o que descarta a possibilidade de terem sido cultivados para essa finalidade (Fior, 2011).

O butiazeiro é uma espécie heliófita, mas também pode ser encontrado no interior das matas próximas aos butiazais (Oliveira et al., 2007).

$\mathrm{O}$ desenvolvimento inicial das palmeiras pode ser dividido em fases. Na primeira, o crescimento iniciase na emissão da primeira folha (eófilo) e estendese até a emissão de folhas pinatissectas (ou pinadas), caracterizando o estádio juvenil (Bernacci et al., 2008). Na produção de mudas de palmeiras, quando a germinação acontece em recipientes coletivos, o transplante deve ser realizado quando as plântulas estiverem com uma ou duas folhas, o que provoca menor estresse, além de evitar o excessivo crescimento das raízes no ambiente de germinação. O transplante deve ser realizado nos meses mais quentes do ano, quando o crescimento das raízes é mais acelerado.
Esse procedimento pode ainda ser conduzido de duas formas: por transplantes sucessivos, para recipientes maiores, conforme as mudas vão crescendo, ou por transplante único, para recipiente grande o suficiente para comportar a muda até a instalação a campo, o que reduz custos, mas pode provocar aumento da perda, principalmente se a irrigação não for manejada adequadamente, pois, em volume maior de substrato, a possibilidade de perda de plantas por encharcamento é maior (Meerow \& Broschat, 2010).

No momento do transplante das mudas, não se recomenda a poda das raízes, pois isso, normalmente, resulta em retrocesso de crescimento ou mesmo na morte de algumas plantas. Portanto, se o sistema radicular supera a altura do recipiente de transplante, pode-se curvá-lo para cima ou em torno do perímetro do interior do recipiente. Contudo, o mais adequado é usar recipientes que comportem todo o comprimento das raízes (Meerow \& Broschat, 2010).

Em cultivos em recipientes, a aplicação de água deve ser feita de maneira que toda ela se infiltre no substrato, sem transbordo. A perda por drenagem, após a irrigação, não deve exceder de 5 a $10 \%$ do volume aplicado sobre o substrato (Arruda et al., 2010). De acordo com Meerow \& Broschat (2010), a irrigação adequada é aquela em que o substrato permanece constantemente úmido, mas nunca saturado.

A capacidade de retenção de água de um substrato divide-se entre água facilmente disponível (volume de água liberado entre tensões negativas de 10 a $50 \mathrm{hPa}$ ), água tamponante (volume de água liberado entre tensões negativas de 50 a $100 \mathrm{hPa}$ ) e água remanescente (volume de água que permanece no substrato depois de aplicada a tensão negativa de $100 \mathrm{hPa}$ ) (De Boodt \& Verdonck, 1972). Avaliações da tensão da água durante cultivos em recipientes sugerem, no entanto, que esses valores são apenas referenciais. Conforme a espécie, o substrato e a situação de cultivo, os limites são variáveis (Gruszynski, 2002).

Conforme Bataglia \& Furlani (2010), para produção de palmeiras em recipientes, os principais materiais utilizados como substrato são a casca de pinus e a fibra de coco, as quais podem ainda ser misturadas a outros componentes, sendo o objetivo a obtenção de uma mistura 
com boa capacidade de aeração e retenção de água. No entanto, conforme esses autores, esses materiais têm pouca capacidade de retenção de nutrientes, por isso é preciso que esses sejam repostos regularmente na forma de soluções nutritivas ou fertilizantes.

Inúmeros trabalhos têm demonstrado as importantes propriedades da casca de pinus, destacando-a como excelente material para uso como substrato para plantas, seja pura, seja em misturas (Machado Neto et al. 2005; Martin et al., 2006; Ludwig et al., 2010).

De acordo com Machado Neto et al. (2005), por suas características físicas e biológicas, a casca de pinus apresenta-se como matéria-prima adequada para utilização como substrato, quer isoladamente, quer em associações, sendo que, quanto menor a granulometria, maior será a capacidade de retenção de água. Esses autores testaram o efeito do extrato aquoso de casca de pinus compostada, em diferentes granulometrias, sobre a germinação de sementes de alface, rabanete, tomate e pepino. Foi constatado que, mesmo utilizando-se granulometrias maiores (12 e $24 \mathrm{~mm}$ ), o que sugere menor decomposição do material, não houve efeito fitotóxico.

Uma opção de fonte de nutrientes para produção de plantas perenes envasadas, ou que precisem permanecer por longo período em viveiro, é o uso de fertilizantes de liberação lenta. Trata-se de sais solúveis em água, agrupados em grânulos de resina orgânica. A solubilização e liberação dos sais contidos nos grânulos depende da degradação da resina, que, por sua vez, está relacionada com o grau de umidade e com a temperatura do substrato. Entre as principais vantagens do uso desses fertilizantes estão a diminuição da mão de obra na adubação e o baixo nível de salinidade da solução do substrato (Kämpf, 2005). Essa salinidade pode ser mensurada por meio de seu potencial osmótico ou pela condutividade elétrica (Taiz e Zeiger, 2004), o que, no entanto, requer uso de equipamentos e metodologias de aplicação complexa. Por isso, a medida mais simples e prática para expressar a concentração das soluções é a mensuração da condutividade elétrica (CE) (Ballarin, 2004).

Conforme Ballarin (2004), diversos trabalhos têm demonstrado que manter $\mathrm{o} \mathrm{pH}$ do substrato junto às raízes das plantas entre 5,0 e 6,0 é de fundamental importância para a estabilidade das membranas das raízes da maioria das espécies, e, consequentemente, para o bom funcionamento da absorção mineral. Kämpf (2005) considera que a faixa de $\mathrm{pH}$ ideal varia muito, de acordo com a espécie a ser cultivada, porém, em geral, para substratos com predominância de material orgânico, a faixa mais adequada é entre 5 e 5,8. Ainda, segundo essa autora, o $\mathrm{pH}$ pode influenciar tanto na disponibilidade de nutrientes quanto na biota do substrato.
São escassos os trabalhos com produção de mudas de palmeiras em recipientes e, além disso, não foram encontrados estudos com esse enfoque para mudas de espécies do gênero Butia. Por isso, este estudo teve por objetivo avaliar o desenvolvimento inicial de mudas de B. odorata, em recipientes com diferentes composições de substrato, de forma a identificar meios adequados para o desenvolvimento das plantas.

\section{MATERIAL E METODOS}

Este estudo foi desenvolvido de novembro de 2009 a julho de 2010, em ambiente de casa de vegetação, sem controle automático de temperatura, em Porto Alegre, $\mathrm{RS}\left(30^{\circ} 03^{\prime} \mathrm{S}\right.$ e $\left.51^{\circ} 10^{\prime} \mathrm{O}\right)$.

Foram utilizadas plântulas germinadas e mantidas, por 60 dias, em casa de vegetação com $70 \%$ de interceptação da intensidade luminosa. Para a germinação homogênea das sementes que deram origem às mudas utilizadas, adotou-se o método de superação de dormência descrito por Fior et al. (2011).

O estudo de desenvolvimento das mudas foi dividido em duas etapas. Na Etapa I, foram testadas densidades de substrato, por combinações de dois componentes de origem orgânica. Na Etapa II, monitorou-se a alteração no desenvolvimento de mudas em decorrência dos níveis de $\mathrm{pH}$, porém mantendo-se as mudas nos recipientes e substratos da etapa anterior.

O substrato utilizado consistiu dos componentes casca de arroz carbonizada (CAC) e casca de pinus composta (CPC), nas proporções volumétricas de 1:0, 2:1, $1: 1,1: 2$ e $0: 1$, respectivamente. A casca de arroz carbonizada foi preparada por meio do sistema de carbonização indicado por Kämpf (2005). A casca de pinus utilizada é um produto comercial.

Antes da mistura, a CPC foi peneirada em malha de 5 $\mathrm{mm}$, desprezando-se as partículas que não passaram pela peneira. Em todos os tratamentos, foi acrescentado fertilizante de liberação lenta (NPK 19-6-10, sem micronutrientes), com tempo de liberação de três a quatro meses, conforme informações do fabricante, na dosagem de três gramas por litro de substrato. $\mathrm{O}$ fertilizante foi incorporado antes do preenchimento dos recipientes de cultivo, os quais constituíram-se de sacos de polietileno preto $(1.150 \mathrm{~mL})$, perfurados nas laterais e na base, completamente preenchidos com substrato. Em cada recipiente, foi estabelecida uma muda.

Antes da mistura do fertilizante, separou-se uma amostra de cada tratamento para análise em laboratório de substrato, na qual foram priorizadas as características físicas das misturas, e uma amostra do CPC para análise em laboratório de solos, visando a determinar as características químicas (Tabela 1). 
Nessa etapa do experimento, utilizou-se delineamento em blocos casualizados, considerando-se como fator de bloqueamento a altura e o número de folhas das mudas, no momento da instalação do experimento: bloco 1: altura média de $14,8 \mathrm{~cm}$ e número médio de folhas de 1,11 ; bloco 2: altura média de $24,3 \mathrm{~cm}$ e número médio de folhas de 1,68 .

$\mathrm{O}$ diâmetro médio das mudas à altura do colo foi de $0,5 \mathrm{~cm}$. Foram estabelecidas 15 plantas por parcela. Logo após o estabelecimento, as mudas foram irrigadas de maneira uniforme e depositadas sobre grade de polietileno rígido, em bancada de concreto, em ambiente de casa de vegetação coberta por telha transparente de fibra de vidro, com tela de sombreamento interna, totalizando $70 \%$ de interceptação da intensidade luminosa.

A irrigação foi realizada diariamente, em quantidades próximas à capacidade de vaso do substrato. Eventualmente, percebeu-se drenagem de 10 a $20 \%$ do conteúdo de cada irrigação.

Aos 90 dias, procedeu-se às leituras da condutividade elétrica (CE) e do $\mathrm{pH}$ do substrato de cinco recipientes de cada parcela, tomados aleatoriamente. O método utilizado foi o pour thru (Cavins, 2000), com base na leitura direta de $\mathrm{pH}$ e CE do lixiviado dos recipientes, após uma hora da saturação com água de irrigação. Em seguida, foram avaliadas todas as plantas do experimento quanto à altura da parte aérea, considerando-se a medida desde a altura do colo até a ponta da maior folha; ao número de folhas por planta e ao diâmetro do caule (altura do colo) de cada planta, com paquímetro.

Após a avaliação, foram selecionadas 64 plantas (16 de cada tratamento) de tamanho mais uniforme possível, e submetidas à Etapa II. Nessa etapa, as plantas fo- ram distribuídas em quatro bandejas de polietileno, sendo quatro plantas de cada tratamento da Etapa I por bandeja (composição do substrato). Em cada bandeja, foi mantida uma lâmina de água de dois a três centímetros de altura, a que foram adicionadas quantidades de hidróxido de sódio a $0,66 \mathrm{M}$ suficientes para que o $\mathrm{pH}$ da solução, em equilíbrio com o substrato, alcançasse os níveis 4,0; 4,9; 5,8 e 6,7; um nível em cada bandeja, com monitoramento diário do $\mathrm{pH}$ da água de cada bandeja. As bandejas foram estabelecidas sobre piso com brita média, em casa de vegetação coberta por fibra de vidro transparente, com $50 \%$ da interceptação da intensidade luminosa (calculada a partir de medições com luxímetro analógico, feitas em diferentes horários do dia). Este procedimento teve como objetivo isolar o efeito do $\mathrm{pH}$ e da fertilidade nos diferentes tratamentos com substrato.

A determinação da quantidade da base para cada nível de $\mathrm{pH}$ foi realizada por titulação com $\mathrm{NaOH}$, de uma amostra de proporções médias dos substratos (uma parte de cada combinação dos cinco tratamentos), a partir da qual calcularam-se os volumes necessários de $\mathrm{NaOH}$ para cada índice de $\mathrm{pH}$ pretendido.

As plantas foram mantidas desta forma por oito dias, sendo então retiradas das bandejas e mantidas, na mesma ordem, diretamente sobre piso com brita média. A partir desta etapa, as plantas foram adubadas por cobertura, com solução nutritiva composta por cloreto de potássio, nitrato de cálcio, sulfato de magnésio, fosfato monoamônio e ureia, na seguinte proporção de nutrientes: $\mathrm{N}: 10,5 ; \mathrm{P}_{2} \mathrm{O}_{5}$ : 6; $\mathrm{K}_{2} \mathrm{O}: 10,7$; S: 4,6; Ca: 3,8; e Mg: 3,2 (adaptado de Broschat, 2000), na concentração de 2 gramas de sais por litro de solução, sendo aplicados 100 mL de solução por

Tabela 1. Análise do substrato casca de pinus compostada, peneirada em malha de $5 \mathrm{~mm}$, utilizado em ambos os experimentos de desenvolvimento de mudas de Butia odorata, com ênfase nas características químicas

\begin{tabular}{lcc}
\hline Determinações & Valores & Método de análise \\
\hline Umidade $(\%)$ & 58 & Gravimetria \\
$\mathrm{pH}$ & 6,8 & Relação 1:5 (em água) \\
Densidade $\left(\mathrm{Kg} \mathrm{m}^{-3}\right)$ & 680 & - \\
Carbono orgânico $(\%)$ & 20 & Combustão úmida - Walkey Black \\
Nitrogênio $(\mathrm{TKN}) \%$ & 0,38 & Kjeldahl \\
Fósforo total \% & 0,16 & Dig. úmida nítrico perclórica ICP-OES \\
Potássio total \% & 0,47 & " \\
Cálcio total \% & 0,89 & " \\
Magnésio total \% & 0,26 & " \\
Enxofre total \% & 0,07 & " \\
Cobre total ppm & 41 & " \\
Zinco total ppm & 68 & " \\
Ferro total \% & 2,5 & Dig. seca ICP-OES \\
Manganês total ppm & 980 & \\
Sódio total ppm & 384 & \\
Boro total ppm & 10 & \\
\hline
\end{tabular}


planta. As aplicações foram realizadas, semanalmente, durante os meses de outono e a cada 21 dias, nos meses de inverno. A cada duas aplicações da solução nutritiva mencionada, foram acrescentados os micronutrientes do meio de cultivo Murashige \& Skoog (1962), $100 \mathrm{~mL}$ da formulação por planta, com pH corrigido para o índice correspondente ao do grupo de plantas a ser adubada, conforme determinado no início da Etapa II.

Ao redor das parcelas, foi mantida uma linha de plantas adicionais, com a função de "bordadura", a fim de isolar o efeito ambiental para as mudas nas diferentes posições.

Para esta etapa, considerou-se o delineamento experimental em blocos ao acaso, tendo como fator de bloqueamento os níveis de $\mathrm{pH}$. Os tratamentos consistiram em cinco combinações dos componentes CAC e CPC, da Etapa I.

Aos 161 dias após início dessa etapa (251 dias desde o início do estudo), procedeu-se às leituras da CE e do $\mathrm{pH}$ do substrato de cinco recipientes de cada parcela, pelo método pour thru. Em seguida, as plantas foram retiradas do substrato, lavadas em água corrente e avaliadas quanto à altura total da parte aérea, ao número de folhas por planta e ao diâmetro do caule, utilizando-se o mesmo procedimento mencionado na Etapa I. Além disso, a parte aérea e o sistema radicular foram avaliados isoladamente, de forma qualitativa, por atribuição de uma nota representativa, de uma escala de 1 a 5, sendo 1 atribuído à parte aérea com mais sintomas de distúrbios nutricionais ou às raízes com menor desenvolvimento e, 5, à parte aérea sem sintomas de distúrbios nutricionais e ao sistema radicular visualmente mais volumoso.

Os dados das variáveis de ambas as etapas foram analisados quanto à distribuição normal (teste de Kolmogorov-Smirnov) e à homocedasticidade (teste de Levene). Em seguida, procedeu-se à análise de variância e à análise de covariância da altura das plantas na primeira etapa, tomando-se como covariável a respectiva altura no início do experimento. Quando os dados não apresentaram distribuição normal, ou apresentaram desigualdade de variâncias, executou-se a análise não paramétrica (teste Kruskal-Wallis, na Etapa 1, e Friedman, na Etapa 2). Quando a variância foi significativa, os dados foram submetidos à análise de comparação de médias, pelo teste de DMS (5\%).

\section{RESULTADOS E DISCUSSÃO}

Não houve perda de mudas por morte durante a condução do experimento. Também não foram observadas pragas ou moléstias que evidenciassem algum sinal ou sintoma nas mudas. A altura média das plantas do tratamento com $100 \%$ de casca de arroz carboni- zada (CAC) foi de $31,3 \mathrm{~cm}$, significativamente inferior à dos demais tratamentos, que apresentaram média de $35,7 \mathrm{~cm}$. Para a variável aumento em altura, verifica-se que os crescimentos médios, durante os 90 dias da Etapa I, foram de 11,6 cm, em substrato CAC e $16,15 \mathrm{~cm}$, nos demais. Nesse período, cada planta emitiu, em média, 1,85 folha, sem diferença estatística entre os tratamentos.

Além da altura das plantas, constatou-se diferença entre os tratamentos para a variável $\mathrm{pH}$ do substrato. No tratamento com apenas $\mathrm{CAC}$, o $\mathrm{pH}$ foi de 3,67, diferindo de todos os demais. Nos tratamentos com maior proporção de casca de pínus compostada (CPC), verificouse $\mathrm{pH}$ mais elevado, porém, mesmo no tratamento com $100 \%$ de CPC, o pH foi bastante baixo, diferindo muito da condição de todos os substratos no início do experimento (Tabelas 1, 2 e 3).

A CE não teve variação significativa entre os tratamentos, estando bem acima da condutividade inicial dos substratos, o que indica que, nessa fase, o fertilizante de liberação lenta, incorporado ao substrato, ainda estava suprindo o meio com nutrientes.

$\mathrm{O}$ pH baixo dos tratamentos com maior proporção de CAC, associado ao fato de este componente do substrato ter apresentado $\mathrm{pH}$ levemente alcalino $(8,0)$, no início do experimento, sugere que o adubo de liberação lenta tenha provocado esta queda do pH (Tabelas $1 \mathrm{e}$ 4). Já nos tratamentos com maior proporção de CPC, que apresentou efeito do fator tamponante da CPC, ainda assim, o pH estava com índice abaixo do verificado para este substrato na análise inicial.

$\mathrm{A} \mathrm{CAC}$, misturada à $\mathrm{CPC}$, afetou diretamente a densidade. Quanto maior seu volume relativo, menos denso tornou-se o substrato, sendo o valor mais baixo de 260 $\mathrm{Kg} \mathrm{m}^{-3}$, enquanto a CPC pura apresentou densidade de $722 \mathrm{Kg} \mathrm{m}^{-3}$. Esses resultados estão de acordo com as informações apresentadas por Minami (1995) que menciona que a casca de arroz carbonizada apresenta forma floculada e baixa densidade.

No entanto, Kämpf (2005) salienta que a densidade não pode ser considerada de forma isolada para escolha de um substrato. Como exemplo, a autora menciona que a casca de arroz carbonizada e a areia apresentam valores de densidade extremamente diferentes, no entanto, quando submetidos à tensão negativa de $100 \mathrm{hPa}$ apresentam capacidades de retenção de água muito semelhantes.

Utilizando-se resíduo de mineração de areia, misturado à casca de arroz carbonizada, para desenvolvimento de mudas de pupunha (Bactris gasipaes), verificou-se que a maior proporção de casca de arroz favoreceu o decréscimo da densidade e a elevação da porosidade total, proporcionando menor microporosidade e maior macroporosidade (Garcia et al., 2011). 
Tratando-se de materiais de origem orgânica, como os deste estudo, o comportamento de algumas propriedades físicas apresenta relação mais estreita com a densidade, quando se compara com materiais de origem mineral. Conforme Kämpf (2005), a densidade desses materiais em um substrato permite interpretar algumas propriedades físicas. Por exemplo, quanto mais alta a densidade do material, mais difícil seu uso em recipientes, quer pela limitação ao crescimento das plantas, quer pela dificuldade no transporte. Segundo o autor, para recipientes com altura entre $20 \mathrm{e}$ $30 \mathrm{~cm}$, que é o caso dos usados neste trabalho, a densidade seca do substrato a ser utilizado deve estar entre 300 e $500 \mathrm{Kg} \mathrm{m}^{-3}$. Ainda, de acordo com De Boodt \& Verdonck (1972), um substrato considerado ideal deve apresentar espaço de aeração entre 20 e $30 \%$ e porosidade total de, pelo menos, $85 \%$. Os resultados apresentados na Tabela 2 mostram que o substrato formado apenas por CPC estaria dentro dessas faixas, sendo, portanto, o mais recomendado dentre as misturas testadas. No entanto, se for levado em conta que a faixa de água disponível, considerada ideal por De Boodt \& Verdonck (1972) para a maioria das espécies, é de $30 \%$, nenhuma das misturas testadas estaria próxima desse valor. Por isso, quando utilizados esses substratos, o monitoramento da demanda hídrica deve ser intenso, uma vez que há menos água disponível para a absorção pelas raízes nos intervalos entre irrigações.

Para $\mathrm{pH}$, o fator bloqueamento apresentou variância significativa (Tabela 3), o que sugere efeito da fase de desenvolvimento das plantas no condicionamento químico do substrato.
$\mathrm{Na}$ segunda etapa do experimento, a composição do substrato foi determinante para o desenvolvimento das mudas, conforme verificado na maioria das variáveis analisadas (Tabela 4). Contudo, para todas as variáveis referentes ao desenvolvimento das plantas que apresentaram diferença entre os tratamentos, o teste de comparação de médias indicou diferença entre as do substrato CAC (100\%) e as dos demais, ou seja, a presença de CPC, mesmo que em baixa proporção, foi suficiente para favorecer o incremento do desenvolvimento vegetativo. Somente o número de folhas por planta não apresentou diferença significativa entre os tratamentos (Tabela 4).

Esse resultado pode estar relacionado tanto com as propriedades físicas dos substratos com CPC, cujas características assemelham-se às consideradas ideais, conforme já mencionado, quanto com o condicionamento químico provocado pelo efeito da CPC (Tabelas 1 e 4).

Mesmo com a correção do pH do substrato e com as soluções de adubação aplicadas ao longo da condução da Etapa II, ao final dessa, não houve diferença significativa de $\mathrm{pH}$ entre os blocos.

Desconsiderando-se as diferenças das variáveis relacionada com o substrato e com a adubação ao longo da condução de todo o experimento, o desenvolvimento das mudas apresentou algumas variações entre as etapas que refletem as condições ambientais do período (Figura 1). Na primeira etapa, quando as plantas foram mantidas sob sombreamento de $70 \%$, por 90 dias, os incrementos médios de número de folhas, de altura e do diâmetro do caule foram de $1,85 \mathrm{~cm}, 15 \mathrm{~cm}$ e 3 $\mathrm{mm}$, respectivamente. Na segunda etapa, em condição

Tabela 2. Análise dos substratos utilizados em ambos os experimentos de desenvolvimento de mudas de Butia odorata, com ênfase nas características físicas

\begin{tabular}{|c|c|c|c|c|c|}
\hline \multirow{2}{*}{ Determinações } & \multicolumn{5}{|c|}{ Tratamento } \\
\hline & $1 *$ & 2 & 3 & 4 & 5 \\
\hline $\mathrm{DU}\left(\mathrm{Kg} \mathrm{m}^{-3}\right)$ & 260 & 454 & 487 & 548 & 722 \\
\hline $\mathrm{DS}\left(\mathrm{Kg} \mathrm{m}^{-3}\right)$ & 131 & 201 & 222 & 241 & 307 \\
\hline $\operatorname{MS}\left(\mathrm{g} 100^{-1}\right)$ & 51 & 44 & 46 & 44 & 42 \\
\hline pH (1:5 - em água) & 8,05 & 7,05 & 6,69 & 6,53 & 6,21 \\
\hline $\mathrm{CE}\left(\mathrm{mS} . \mathrm{cm}^{-1}\right)-1: 5$ - em água) & 0,099 & 0,092 & 0,894 & 0,096 & 0,117 \\
\hline $\mathrm{pT}\left(\mathrm{m}^{3} \mathrm{~m}^{-3}\right)$ & 0,81 & 0,86 & 0,84 & 0,81 & 0,85 \\
\hline $\mathrm{EA}\left(\mathrm{m}^{3} \mathrm{~m}^{-3}\right)$ & 0,57 & 0,52 & 0,47 & 0,41 & 0,32 \\
\hline $\operatorname{AFD}\left(\mathrm{m}^{3} \mathrm{~m}^{-3}\right)$ & 0,12 & 0,11 & 0,1 & 0,09 & 0,08 \\
\hline $\operatorname{AT}\left(\mathrm{m}^{3} \mathrm{~m}^{-3}\right)$ & 0,01 & 0,02 & 0,02 & 0,02 & 0,02 \\
\hline $\operatorname{AD}\left(m^{3} m^{-3}\right)$ & 0,14 & 0,13 & 0,12 & 0,11 & 0,11 \\
\hline CRA $10\left(\mathrm{~m}^{3} \mathrm{~m}^{-3}\right)$ & 0,23 & 0,34 & 0,37 & 0,4 & 0,54 \\
\hline CRA $50\left(\mathrm{~m}^{3} \mathrm{~m}^{-3}\right)$ & 0,11 & 0,23 & 0,27 & 0,31 & 0,45 \\
\hline CRA $100\left(\mathrm{~m}^{3} \mathrm{~m}^{-3}\right)$ & 0,09 & 0,22 & 0,25 & 0,29 & 0,43 \\
\hline
\end{tabular}

*1: Casca de arroz carbonizada (CAC); 2: CAC + Casca de pinus compostada (CPC) (2:1); 3: CAC + CPC (1:1); 4: CAC + CPC (1:2); e 5: CPC - Proporções volumétricas; DU: densidade úmida; DS: densidade seca; MS: matéria Seca; CE: condutividade elétrica; pT: porosidade total; EA: espaço de aeração; AFD: água facilmente disponível; AT: água tanponante; AD: água disponível; CRA: capacidade de retenção de água. 
de maior intensidade luminosa $(50 \%)$ e de tempo mais prolongado (160 dias), os incrementos de número de folhas, de altura e de diâmetro do caule das mesmas variáveis foi de $2,37 \mathrm{~cm}, 5,3 \mathrm{~cm}$ e $8 \mathrm{~mm}$, respectivamente. À primeira impressão, percebe-se o menor crescimento em altura na segunda etapa. Porém, ao dividir o incremento de cada variável pelo número de dias da etapa correspondente, verifica-se que somente o diâmetro do caule manteve a intensidade de crescimento $(0,0033 \mathrm{~mm}$ por dia, igualmente em ambas as etapas). Voltando-se para as variáveis ambientais do período, verifica-se que a primeira etapa foi conduzida no período de primavera e verão (meados de novembro a meados de fevereiro) e, a segunda, no final do verão, todo o outono e início do inverno (fevereiro a julho). Esta informação remete a diferenças de temperatura e de horas de sol por dia, nas duas etapas. No entanto, o fato de as plantas terem mantido o crescimento do diâmetro do caule, mesmo no período ambientalmente desfavorável, sugere que a maior intensidade luminosa, pela mudança de casa de vegetação, tenha compensado a possível deficiência dos fatores temperatura e horas de luz da segunda etapa.

É provável que, no início da segunda etapa, quando a temperatura média ainda se mantinha elevada, o aumento da intensidade luminosa tenha favorecido um crescimento mais acelerado das plantas em diâmetro do caule, tendo-se, a seguir, estabilizado no período de temperatura mais baixa, o que, na média, resultou em um crescimento diário idêntico entre os períodos. Essa observação indica que, embora plântulas de butiazeiro sejam encontradas na

Tabela 3. Desenvolvimento de mudas de Butia odorata submetidas à primeira etapa do experimento em tratamentos com substratos em combinações dos componentes: casca de pinus compostada (CPC) e casca de arroz carbonizada (CAC), aos 91 dias após o estabelecimento

\begin{tabular}{|c|c|c|c|c|c|c|c|}
\hline \multirow[b]{2}{*}{ Substrato } & \multicolumn{2}{|c|}{ Avaliação do substrato } & \multicolumn{5}{|c|}{ Avaliação das plantas } \\
\hline & $\begin{array}{c}\mathrm{CE}^{1} \\
\left(\mu \mathrm{S} . \mathrm{cm}^{-1}\right)\end{array}$ & $\mathrm{pH}$ & Altura (cm) & $\mathrm{N}^{0}$ de Folhas & $\begin{array}{c}\text { Diâmetro do } \\
\text { caule }(\mathrm{cm})\end{array}$ & $\begin{array}{l}\text { Aumento em } \\
\text { altura (cm) }\end{array}$ & $\begin{array}{l}\text { Aumento em } \\
n^{\circ} \text { de folhas }\end{array}$ \\
\hline $1^{2}$ & 4,543 & $3,67 d^{3}$ & $31,3 \mathrm{~b}$ & 3,2 & 0,81 & $11,6 \mathrm{~b}$ & 1,8 \\
\hline 2 & 4,588 & $3,90 \mathrm{c}$ & $36,0 \mathrm{a}$ & 3,1 & 0,79 & $16,1 \mathrm{a}$ & 1,9 \\
\hline 3 & 4,517 & $4,06 \mathrm{~b}$ & $35,3 \mathrm{a}$ & 3,3 & 0,81 & $14,8 \mathrm{a}$ & 1,9 \\
\hline 4 & 5,049 & $4,19 \mathrm{a}$ & $35,2 \mathrm{a}$ & 3,3 & 0,80 & $17,1 \mathrm{a}$ & 1,8 \\
\hline 5 & 5,499 & $4,15 \mathrm{a}$ & $36,3 \mathrm{a}$ & 3,4 & 0,82 & $16,6 \mathrm{a}$ & 1,9 \\
\hline Análise & ANOVA & ANOVA & ANCOVA & Friedman ${ }^{4}$ & ANOVA & ANOVA & Friedman \\
\hline P (Trat) & 0,389 & $<0,01$ & $<0,01$ & 0,342 & 0,895 & $<0,01$ & 0,901 \\
\hline $\mathrm{P}($ Bloco $)$ & 0,691 & $<0,01$ & 0,012 & 1,000 & $<0,01$ & 0,247 & 1,000 \\
\hline Média & 4,84 & 3,99 & 34,82 & 3,26 & 0,81 & 15,24 & 1,86 \\
\hline $\mathrm{CV}(\%)$ & 17,18 & 2,56 & 13,58 & - & 15,58 & 31,31 & - \\
\hline
\end{tabular}

${ }^{1} \mathrm{CE}$ : Condutividade elétrica. 1: Casca de arroz carbonizada (CAC); 2 : CAC + Casca de pinus compostada (CPC) (2:1); 3: CAC + CPC (1:1); 4: CAC + CPC (1:2); e 5: CPC - Proporções volumétricas. ${ }^{3}$ Médias seguidas de mesma letra na coluna não diferem estatisticamente pelo teste DMS a 5\%. ${ }^{4}$ ANOVA não paramétrica, teste de Friedman.

Tabela 4. Desenvolvimento de mudas de Butia odorata avaliadas ao final da segunda etapa do experimento com substratos em combinações dos componentes: casca de pinus compostada (CPC) e casca de arroz carbonizada (CAC), aos 250 dias após o estabelecimento, e a 160 dias em quatro níveis de $\mathrm{pH}$

\begin{tabular}{|c|c|c|c|c|c|c|c|c|c|c|}
\hline Substrato & $\begin{array}{c}\mathrm{CE} \\
\left(\boldsymbol{\mu S . \mathrm { cm } ^ { - 1 } )}\right.\end{array}$ & pH & $\begin{array}{l}\text { Altura } \\
(\mathrm{cm})\end{array}$ & $\begin{array}{c}\mathbf{N}^{\mathbf{0}} \\
\text { Folhas }\end{array}$ & $\begin{array}{c}\text { Compr. } \\
\text { Raízes } \\
\text { (cm) }\end{array}$ & $\begin{array}{c}\mathrm{N}^{\circ} \\
\text { Raízes }\end{array}$ & $\begin{array}{l}\text { Diâm. a } \\
\text { alt. colo } \\
(\mathrm{mm})\end{array}$ & $\begin{array}{l}\text { Nota / } \\
\text { raízes }\end{array}$ & $\begin{array}{l}\text { Nota / } \\
\text { parte } \\
\text { aérea }\end{array}$ & $\begin{array}{l}\text { Increm. } \\
\text { em altura } \\
(\mathrm{cm})\end{array}$ \\
\hline 1 & $114,95 \mathrm{~d}^{* *}$ & $4,27 \mathrm{c}$ & $27,87 \mathrm{~b}$ & $4,88 \mathrm{~ns}$ & $16,25 b$ & $3,69 \mathrm{~b}$ & $9,47 \mathrm{~b}$ & $1,75 b$ & $1,63 \mathrm{~b}$ & $1,39 \mathrm{~b}$ \\
\hline 2 & $258,80 \mathrm{c}$ & $4,47 \mathrm{~b}$ & $35,23 \mathrm{a}$ & $5,33 \mathrm{~ns}$ & $20,97 \mathrm{a}$ & $4,92 \mathrm{a}$ & $13,65 \mathrm{a}$ & $3,73 \mathrm{a}$ & $3,00 \mathrm{a}$ & $4,84 \mathrm{ab}$ \\
\hline 3 & $318,28 \mathrm{~b}$ & $4,59 \mathrm{ab}$ & $38,39 \mathrm{a}$ & $5,35 \mathrm{~ns}$ & $20,82 \mathrm{a}$ & $5,50 \mathrm{a}$ & $14,21 \mathrm{a}$ & $3,71 \mathrm{a}$ & $3,17 \mathrm{a}$ & $8,35 \mathrm{a}$ \\
\hline 4 & $367,25 \mathrm{~b}$ & $4,65 \mathrm{a}$ & $38,38 \mathrm{a}$ & $5,58 \mathrm{~ns}$ & $20,79 a$ & $5,33 \mathrm{a}$ & $14,53 \mathrm{a}$ & $3,52 \mathrm{a}$ & $3,40 \mathrm{a}$ & $7,79 \mathrm{a}$ \\
\hline 5 & $452,89 a$ & $4,70 \mathrm{a}$ & $39,22 \mathrm{a}$ & $5,69 \mathrm{~ns}$ & $19,53 \mathrm{a}$ & $5,63 \mathrm{a}$ & $14,72 \mathrm{a}$ & $3,56 \mathrm{a}$ & $3,31 \mathrm{a}$ & $7,76 \mathrm{a}$ \\
\hline Valor P (Substr.) & $<0,001$ & $<0,001$ & 0,006 & 0,168 & 0,021 & 0,003 & $<0,001$ & $<0,001$ & 0,006 & 0,006 \\
\hline Valor P(Bloco) & 0,031 & 0,335 & 0,196 & 0,327 & 0,91 & 0,689 & 0,478 & 0,907 & 0,974 & 0,784 \\
\hline Média & 302,43 & 4,54 & 35,82 & 5,37 & 19,67 & 5,01 & 13,31 & 3,25 & 2,90 & 6,03 \\
\hline DMS* & 59,28 & 0,14 & 5,75 & - & 2,95 & 0,90 & 2,00 & 0,82 & 0,91 & 3,63 \\
\hline
\end{tabular}

1: Casca de arroz carbonizada (CAC); 2: CAC + Casca de pinus compostada (CPC) (2:1); 3: CAC + CPC (1:1); 4: CAC + CPC (1:2); e 5: CPC - Proporções volumétricas. * DMS: diferença mínima significativa a 95\% de confiabilidade; **: Médias seguidas de mesma letra na coluna não diferem significativamente pelo teste DMS; ns: médias sem diferença estatística significativa; CE: condutividade elétrica; Nota da parte aérea e raízes: escala de 1 a 5 atribuída ao aspecto visual.

Rev. Ceres, Viçosa, v. 61, n.5, p. 706-714, set/out, 2014 


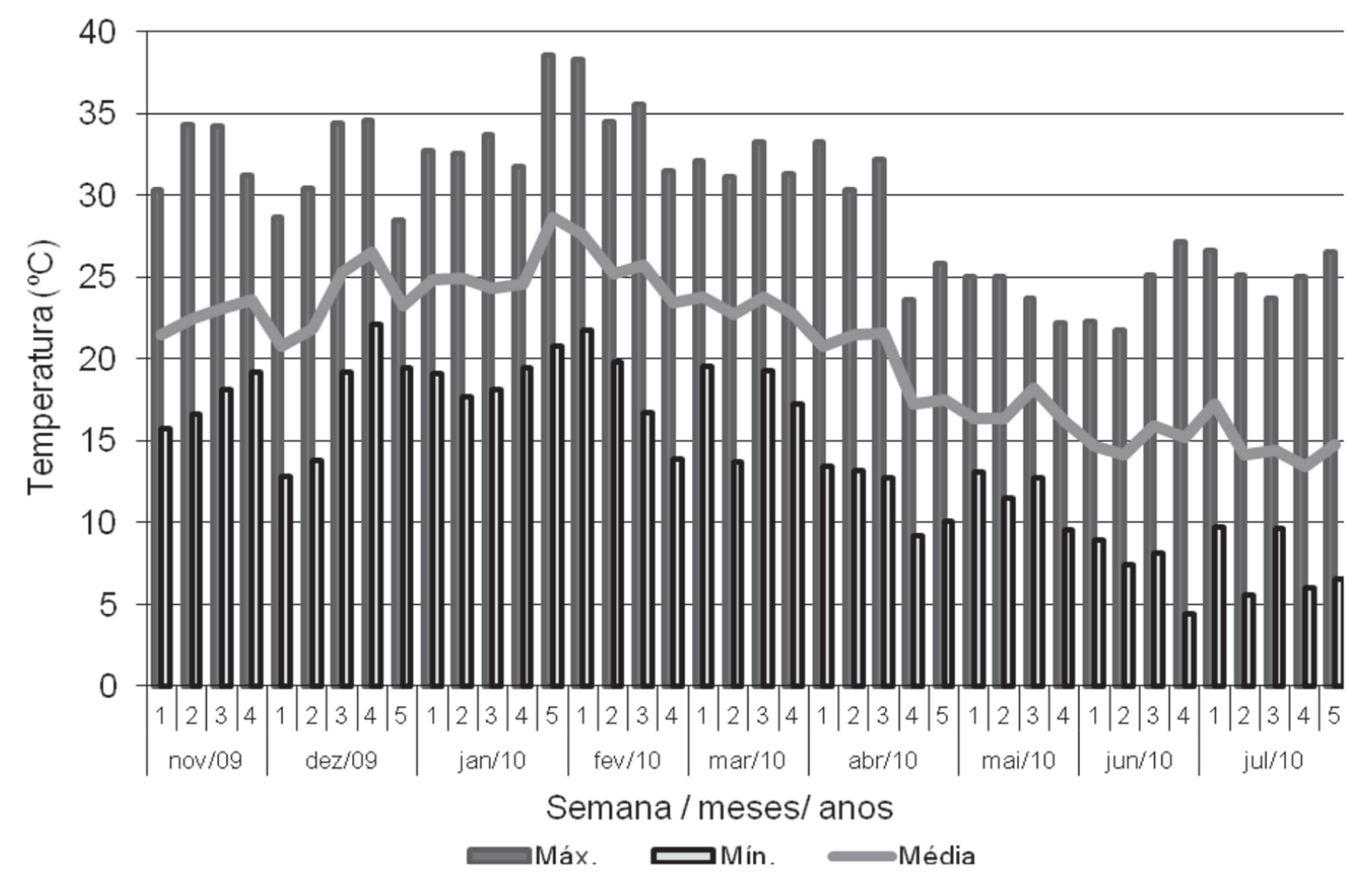

Figura 1. Temperaturas máximas e mínimas absolutas e médias semanais do ambiente externo à casa de vegetação, de todo o período de condução do experimento com desenvolvimento de mudas de Butia odorata. (Fonte: Instituto Nacional de Meteorologia - INMET $8^{\circ}$ Distrito de Meteorologia - Porto Alegre.

natureza em ambiente sombreado (Oliveira et al., 2007), o crescimento das mudas ocorre de forma mais acentuada em ambiente com maior intensidade luminosa.

O desenvolvimento de mudas de butiazeiro em recipientes parece ser afetado pela densidade do substrato. Contudo, essa variável esteve diretamente relacionada com o pH, em função da característica do substrato utilizado. Por causa das variações ocorridas ao longo das duas etapas do experimento, e por não terem sido evidenciados sintomas nas plantas, pode-se inferir que $B$. odorata tolera amplitudes de $\mathrm{pH}$ entre neutro a fortemente ácido.

A manutenção das plantas em ambiente com maior intensidade luminosa, durante os meses de outono e inverno, pode compensar a queda da temperatura e a diminuição das horas de luz do dia, mantendo as mudas em crescimento nesse período.

\section{CONCLUSÕES}

O desenvolvimento inicial de mudas de B. odorata em recipientes foi desfavorecido quando utilizado substrato formado apenas por casca de casca de arroz carbonizada, o que não aconteceu quando utilizada casca de pinus compostada (pura ou em mistura com a casca de arroz).

Considerando-se os limites observados, o $\mathrm{pH}$ do substrato não é fator preponderante na fase inicial do crescimento das mudas da espécie.

\section{REFERENCIAS}

Arruda FB, Pires RCM \& Sakai E (2010) Irrigação. In: Mathes LAF \& Uzzo RP (Org.) (2010) Palmeiras Ornamentais: produção e cultivo. Campinas, FUNDAG. p.31-42.

Ballarin MCC (2004) Nutrición mineral y abonado para cultivo en substratos de baja actividad química. In: Barbosa JG, Martinez HEP, Pedrosa MW \& Sediyama, MAN (2004) Nutrição e adubação de plantas cultivadas em substrato. Viçosa, UFV. p.92-96

Bataglia OC \& Furlani PR (2010) Adubação. In: Mathes LAF \& Uzzo RP (ORGS.) Palmeiras Ornamentais: produção e cultivo. Campinas, FUNDAG. p.43-57.

Bernacci LC, Martins FR \& Santos FAM (2008) Estrutura de estádios ontogenéticos em população nativa da palmeira Syagrus romanzoffiana (Cham.) Glassman (Arecaceae). Acta Botanica Brasilica, 22:119-130.

Broschat TK (2000) Palm nutrition guide. Gainesville, University of Florida. 6p. (Circular SS-ORH-02).

Cavins TJ, Gibson JL, Whipker BE \& Fonteno WC (2000) pH and EC Meters - Tool for Substrate Analysis. Raleigh, NC State University. Florex 001.

De Boodt M \& Verdonck O (1972) The physical properties of the substrates in horticulture. Acta Horticulturae, 26:37-44.

Fior CS, (2011) Propagação de Butia odorata (Barb. Rodr.) Noblick \& Lorenzi. Tese de Doutorado. Programa de Pós Graduação em Fitotecnia da UFRGS, Porto Alegre. 186p.

Fior CS Rodrigues LR, Leonhardt C \& Schwarz SF (2011) Superação de dormência em sementes de Butia capitata. Ciencia Rural, 41:11501153.

Garcia VA, Modolo VA, Lagôa AMMA, Nomura ES \& Sáes LA (2011) Características do resíduo de mineração de areia como componente de substratos para a produção de mudas de pupunheira (Bactris gasipaes Kunth). Revista Árvore, 35:595-604.

Rev. Ceres, Viçosa, v. 61, n.5, p. 706-714, set/out, 2014 
Geymonat G \& Rocha N (2009) M'botia. Ecosistema único en el mundo. Castillos, Casa Ambiental. 405p.

Gruszynski C (2002) Resíduo agro-industrial "casca de tungue" como componente de substrato para plantas. Dissertação de mestrado. Programa de Pós-graduação em Fitotecnia da UFRGS, Porto Alegre. 100p.

Kämpf AN (2005) Produção comercial de plantas ornamentais. $2^{\mathrm{a}} \mathrm{ed}$ Guaíba, Agrolivros. 256p.

Lorenzi H, Noblick LR, Kahn F \& Ferreira E (2010) Flora brasileira Lorenzi: Arecaceae (palmeiras). Nova Odessa, Instituto Plantarum. 367p

Ludwig F, Guerrero AC, Fernandes DM \& Boas RLV (2010) Análise de crescimento de gérbera de vaso conduzida em diferentes substratos. Horticultura Brasileira, 28:70-74.

Machado Neto NB, Custódio CC, Carvalho PR, Yamamoto NL \& Cacciolari C (2005) Casca de pinus: avaliação da capacidade de retenção de água e da fitotoxicidade. Colloquium Agrariae, 1:19-24

Martin TN, Lima LB, Rodrigues A, Girardi E, Fabri EG \& Minami K (2006) Utilização de vermiculita, casca de pinus e carvão na produção de mudas de pepino e de pimentão. Acta Scientiarum Agronomy, 28:107-113.
Meerow AW \& Broschat TK (2010) Container Production of Palms. Disponível em: <http://edis.ifas.ufl.edu/CN010>. Acessado em: 17 de novembro de 2011

Minami K (1995) Produção de mudas de alta qualidade em horticultura. São Paulo, Fundação Salim Farah Maluf. 128p.

Murashige T \& Skoog F (1962) A revised medium for rapid growth and bioassays with tobacco tissue cultures. Physiologia Plantarum, 15:473-497.

Oliveira MLAA, Senna R, Neves MTMB, Blank M \& Boldrini II (2007) Flora e Vegetação. In: Becker FG, Ramos RA, \& Moura LA (Org.) Biodiversidade. Regiões da Lagoa do Casamento e dos Butiazais de Tapes. Planície Costeira do Rio Grande do Sul, Ministério do Meio Ambiente. p.84-111

Soares KP \& Longhi SJ (2011) Uma nova espécie de Butia (Becc.) Becc. (Arecaceae) para o Rio Grande do Sul, Brasil. Ciência Florestal, 21:203208

Taiz L \& Zeiger E (2004) Fisiologia vegetal. Porto Alegre, Artmed. 719p.

Tonietto A, Schlindwein G \& Tonietto SM (2009) Usos e potencialidades do butiazeiro. Porto Alegre, Fepagro. 28p. (Circular Técnica, 26) 